\title{
Preparation of Antisulphuric Paperboard and Its Application in Packaging Industrial Silver Products
}

\author{
Linlin $\mathrm{Yu}^{1, \mathrm{a}}$, Junyan Huang ${ }^{1, \mathrm{~b}}$, Huizhong Zhang ${ }^{2}$, \\ Wensheng Wang ${ }^{1}$, Xiaojuan Shi ${ }^{1}$ \\ ${ }^{1}$ Dalian Polytechnic University, Dalian, Liaoning 116034, China \\ ${ }^{2}$ Tat Seng Packaking(Suzhou) Co., Ltd., Suzhou, Jiangshu 215155, China \\ a739417321@qq.com, bhuangjunyan@126.com
}

\begin{abstract}
Keywords: Antisulphuric coating; Coated paperboard; Industrial silver products; Test and analysis of antisulphuric packaging.

Abstract: An antisulphuric coating manufactured by U.S. michelman was coated on the case board to prepare antisulphuric packaging paperboard. The silver strip samples were wrapped in antisulphuric packaging paperboard under laboratory condition in a simulated extreme sulfur-containing atmosphere, then the corrosion status of silver strip samples were observed and the effect of antisulphuric packaging of the coated paperboard with different coating weight were tested and analysed. The results show that antisulphuric packaging paperboard with coating weigh $18-22 \mathrm{~g} / \mathrm{m}^{2}$ applied to wrap industrial silver products, its comprehensive protective effect and physical properties are better, and it can avoid the economic loss caused by the corrosion of silver products due to exposure to the industrial atmosphere.
\end{abstract}

\section{Introduction}

In order to study a kind of coated packaging paperboard with antisulphuric function ${ }^{[1,2]}$, the experiment chooses the coating imported from U.S. michelman which can prevent sulfide to prepare antisulphuric packaging paperboard ${ }^{[3-4]}$. The experiment chooses coating weight $8-24 \mathrm{~g} / \mathrm{m}^{2}$, and coating process was studied at $2 \mathrm{~g} / \mathrm{m}^{2}$ intervals. Then silver strip samples were wrapped in antisulphuric packaging paperboard with different coating weight, and placed in laboratory in a simulated extreme sulfur-containing atmosphere. The antisulphuric packaging paperboard with different coating weight were analyzed by scanning electron microscope SEM, its image of micro-changes within the paperboard were modulated by a variety of physical signals which were excited by a thin focused electron beam on the surface of the sample ${ }^{[5]}$. The energy spectrum of the protective silver strip samples were analyzed by use of EDS, and the Lab value of the silver strips were used to characterize the corrosion degree, thus the best value of the coating weight was analyzed.

\section{Experiment}

Raw material. The coating which can prevent sulfide imported from U.S. michelman; the case board provided by Tat Seng Packaking(Suzhou) Co., Ltd.; Hydrochloric acid, sodium chloride, iron sulfide, sodium hydroxide, lead acetate test paper, silver strip $(10 \times 10 \mathrm{~mm})$ were respectively purchased in Kaifeng City Donglian Petrochemical Co., Ltd., Tianjin Fuchen Chemical Reagent Factory, Tianjin Damao Chemical Reagent Factory, Tianjin Guangfu Science and Technology Development Co., Ltd., Shanghai Sanaisi Reagent Co., Ltd. and Mass Silver Workshop.

Experimental preparation. The experiment takes the sterling silver strip for research instead of the industrial silver parts and silver plated products. According to the preliminary experiment, the coating from U.S. michelman was coated on case board to prepare antisulphuric packaging paperboard with different coating weight range between $8-24 \mathrm{~g} / \mathrm{m}^{2}$. The silver strips were polished with $1000-7000$ eye per inch metallographic sandpaper, washed with deionized water, dried, made silver samples. And then the silver strip samples were wrapped in antisulphuric packaging paperboard with different coating 
weight, and placed in laboratory in a simulated extreme sulfur-containing atmosphere, regular observed and tested.

\section{Test experiment}

(1)The samples of silver strip and antisulphuric packaging paperboard were made for SEM and EDS. The surface micro analysis of silver strip samples and antisulphuric packaging paperboard and the energy spectrum analysis before and after corrosion were taken, and the corrosion degree of the surface of silver strip samples were observed.

(2) The surface Lab of silver strip samples was characterized by the spectrophotometer.

(3) The physical properties of antisulphuric packaging paperboard with different coating weight were tested, including bursting strength, puncture strength, flat compression strength and edgewise-crushed resistance.

\section{Results and discussion}

Comparison of the fiber structure of the paperboard with different coating weight. The SEM specimen image of case board and coated paperboard is shown in Fig. 1. The image A is the SEM image which has been magnified 200 times. It can be seen that the paper fiber twisted together and formed a network structure ${ }^{[6]}$, but the fiber gap is big. The image B and C are enlarged 500 times SEM image, from image we can see that, with the increase in the coating weight, the fibers are crosslinked and the gap of fiber is attached to the mucosa, the fiber binding force is increased, meanwhile the fiber morphology and intertwined situation also determine fiber mechanical strength ${ }^{[7]}$.

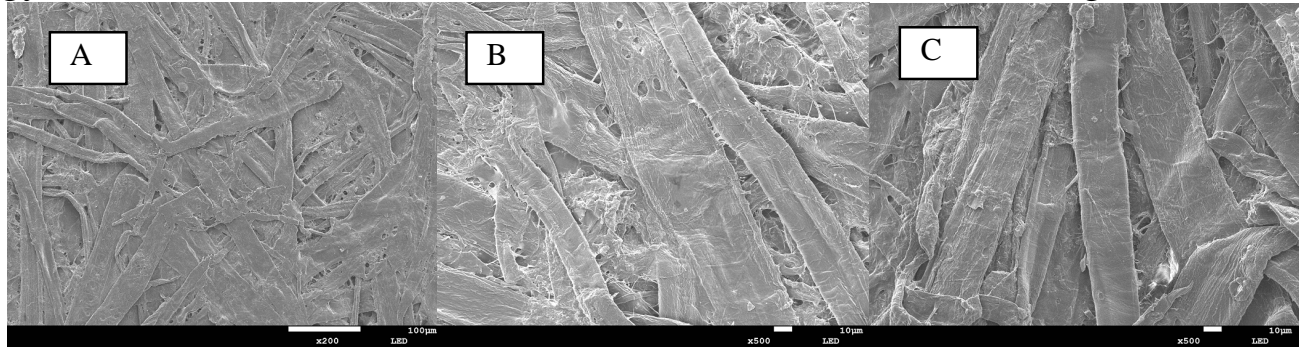

Fig. 1 case board and coated paperboard's SEM

A is case board; B and C are coated paperboard with coating weight respectively $18 \mathrm{~g} / \mathrm{m}^{2}$ and $24 \mathrm{~g} / \mathrm{m}^{2}$

Analysis of surface corrosion degree of silver strip samples. There are three different corrosion degrees of silver strip samples in Fig. 2, the image A is silver strip sample wrapped in coated paperboard with coating weight $18-24 \mathrm{~g} / \mathrm{m}^{2}$, and placed in extreme hydrogen sulfide environment. The B silver strip sample wrapped in coated paperboard which coating weight is below $16 \mathrm{~g} / \mathrm{m}^{2}$, put in extreme hydrogen sulfide environment. The $\mathrm{C}$ silver strip sample wrapped in uncoated paperboard. It can be seen from Fig. 2 that corrosion degrees of silver strip samples wrapped in coated paperboard are lower than samples wrapped in uncoated paperboard. From this, we can see that coated paperboard coated with antisulphuric coating from U.S. michelman can effectively inhibit silver strip corrosion.
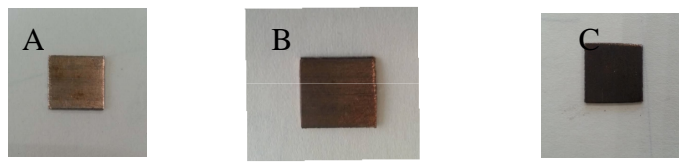

Fig. 2 Three kinds of silver pieces with different degrees of corrosion

Fig. 3 is EDS energy spectrum of A silver strip sample in Fig. 2, the extent of corrosion is determined by observing the surface energy spectrum of silver strip and its $\mathrm{S}$ content. From Tab. 1 and Fig. 3, it can be seen that the content of $\mathrm{S}$ was $0.09 \%$ in the wt $\%$. 
Tab. 1 Energy-dispersive X-ray spectroscopy's data of A silver

\begin{tabular}{|c|c|c|c|c|c|c|c|}
\hline Element & Line Type & Apparent Concentration & k Ratio & $\mathrm{Wt} \%$ & Wt\% Sigma & Standard Label & Factory Standard \\
\hline $\mathrm{C}$ & K series & 3.40 & 0.03401 & 5.51 & 0.09 & C Vit & Yes \\
\hline $\mathrm{O}$ & $\mathrm{K}$ series & 1.76 & 0.00591 & 5.59 & 0.14 & $\mathrm{SiO}_{2}$ & Yes \\
\hline $\mathrm{Al}$ & $\mathrm{K}$ series & 0.07 & 0.00051 & 0.11 & 0.02 & $\mathrm{Al}_{2} \mathrm{O}_{3}$ & Yes \\
\hline $\mathrm{Si}$ & $\mathrm{K}$ series & 0.78 & 0.00618 & 0.98 & 0.03 & $\mathrm{SiO}_{2}$ & Yes \\
\hline $\mathrm{S}$ & K series & 0.09 & 0.00079 & 0.09 & 0.02 & $\mathrm{FeS}_{2}$ & Yes \\
\hline $\mathrm{Fe}$ & K series & 0.43 & 0.00427 & 0.45 & 0.04 & $\mathrm{Fe}$ & Yes \\
\hline $\mathrm{Ag}$ & L series & 87.03 & 0.87026 & 87.27 & 0.17 & $\mathrm{Ag}$ & Yes \\
\hline Total & & & & 100.00 & & & \\
\hline
\end{tabular}

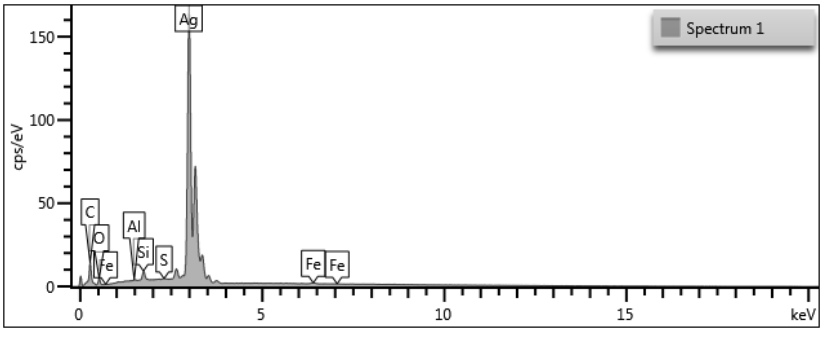

Fig. 3 Energy-dispersive X-ray spectroscopy of A silver

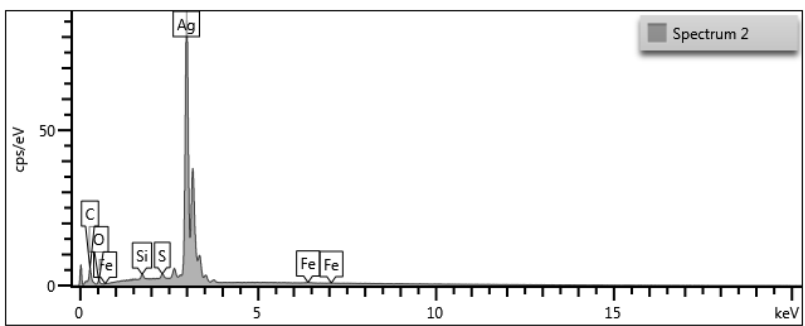

Fig. 4 Energy-dispersive X-ray spectroscopy of B silver

From Fig. 4 and Tab. 2, we can observe the surface energy spectrum of B silver strip and its S content. It can be seen from Tab. 2 that the content of S in the wt $\%$ was $0.51 \%$ and higher than that of A silver strip $0.42 \%$.

Tab. 2 Energy-dispersive X-ray spectroscopy's data of B silver

\begin{tabular}{|c|c|c|c|c|c|c|c|}
\hline Element & Line Type & Apparent Concentration & k Ratio & $\mathrm{Wt} \%$ & Wt\% Sigma & Standard Label & Factory Standard \\
\hline $\mathrm{C}$ & $\mathrm{K}$ series & 2.33 & 0.02325 & 4.00 & 0.10 & C Vit & Yes \\
\hline $\mathrm{O}$ & $\mathrm{K}$ series & 0.79 & 0.00265 & 2.74 & 0.15 & $\mathrm{SiO}_{2}$ & Yes \\
\hline $\mathrm{Si}$ & $\mathrm{K}$ series & 0.44 & 0.00347 & 0.59 & 0.03 & $\mathrm{SiO}_{2}$ & Yes \\
\hline $\mathrm{S}$ & $\mathrm{K}$ series & 0.50 & 0.00431 & 0.51 & 0.03 & $\mathrm{FeS}_{2}$ & Yes \\
\hline $\mathrm{Fe}$ & $\mathrm{K}$ series & 0.15 & 0.00153 & 0.17 & 0.05 & $\mathrm{Fe}$ & Yes \\
\hline $\mathrm{Ag}$ & L series & 87.14 & 0.87138 & 92.00 & 0.18 & $\mathrm{Ag}$ & Yes \\
\hline
\end{tabular}

From Fig. $5 \mathrm{C}$ silver EDS energy spectrum and the data in Tab. 3, it can be seen that the corrosion degree of the silver wrapped in uncoated paperboard is highest, and the mass fraction could reach $1.31 \%$, its surface is very easy to produce black or yellow film, corrosion and discoloration. Discoloration of silver not only affects the product performance and appearance of reflective performance, but also reduces the electrical conductivity, solderability, thus causing great losses to the enterprise.

Tab. 3 Energy-dispersive X-ray spectroscopy's data of C silver

\begin{tabular}{cccccccc}
\hline Element & Line Type & Apparent Concentration & k Ratio & Wt\% & Wt\% Sigma & Standard Label & Factory Standard \\
\hline $\mathrm{C}$ & K series & 2.42 & 0.02422 & 4.50 & 0.10 & $\mathrm{C} \mathrm{Vit}$ & Yes \\
$\mathrm{O}$ & K series & 0.88 & 0.00297 & 3.00 & 0.15 & $\mathrm{SiO}_{2}$ & Yes \\
$\mathrm{Na}$ & K series & 0.08 & 0.00034 & 0.15 & 0.04 & $\mathrm{Albite}$ & Yes \\
$\mathrm{Al}$ & K series & 0.07 & 0.00048 & 0.11 & 0.03 & $\mathrm{Al}_{2} \mathrm{O}_{3}$ & Yes \\
$\mathrm{Si}$ & K series & 0.66 & 0.00522 & 0.86 & 0.03 & $\mathrm{SiO}_{2}$ & Yes \\
$\mathrm{S}$ & K series & 1.29 & 0.01116 & 1.31 & 0.03 & $\mathrm{FeS}_{2}$ & Yes \\
$\mathrm{Fe}$ & K series & 0.24 & 0.00237 & 0.26 & 0.05 & $\mathrm{Fe}$ & Yes \\
$\mathrm{Ag}$ & L series & 85.51 & 0.85510 & 89.81 & 0.19 & $\mathrm{Ag}$ & Yes \\
\hline
\end{tabular}




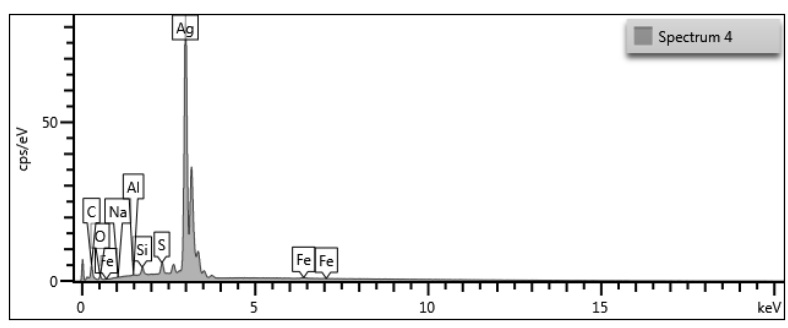

Fig. 5 Energy-dispersive X-ray spectroscopy of C silver

The corrosion degree of silver strip samples is characterized by Lab value. Fig. 6 is the trend of Lab value over time which are measured at each interval same time when silver strip samples wrapped in coated paperboard with different coating weight, and placed in laboratory in a simulated extreme sulfur-containing atmosphere. The $\mathrm{L}$ value is more higher, the corrosion degree is more lower. The number 1-7 are coated paperboard which coating weight respectively are $8-12 \mathrm{~g} / \mathrm{m}^{2}, 14-16 \mathrm{~g} / \mathrm{m}^{2}$, $16-18 \mathrm{~g} / \mathrm{m}^{2}, 18-20 \mathrm{~g} / \mathrm{m}^{2}, 20-22 \mathrm{~g} / \mathrm{m}^{2}, 22-24 \mathrm{~g} / \mathrm{m}^{2}$. From Fig. 6 it can be obviously seen, at the same time, the protection effect of coated paperboard with coating weight $8-12 \mathrm{~g} / \mathrm{m}^{2}$ is poor, the protective effect of coated paperboard with coating weight $14-22 \mathrm{~g} / \mathrm{m}^{2}$ shows a rising trend. At equal measurement time interval, numerical change of coated paperboard with coating weight $22-24 \mathrm{~g} / \mathrm{m}^{2}$ is smaller, and protection effect is no big change. So it can been seen that coating weight should not be too big, not only increasing effect is not ideal, and the production cost rise.

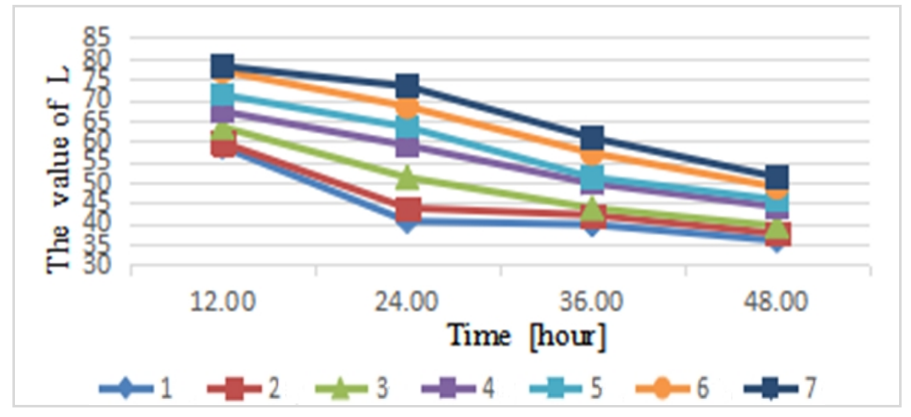

Fig. 6 The trend of Lab value over time

Comparison of the physical properties of antisulphuric packaging paperboard. In the process of preparing antisulphuric packaging paperboard, in addition to antisulphuric performance, the physical properties of coated paperboard such as bursting strength, puncture strength, flat compression strength and edgewise-crushed resistance are also very important during handling, storing and transportation. The following four groups of data are physical properties data chart of the coated paperboard with different coating weight, each value is mean of 10 sets data in same coating weight.

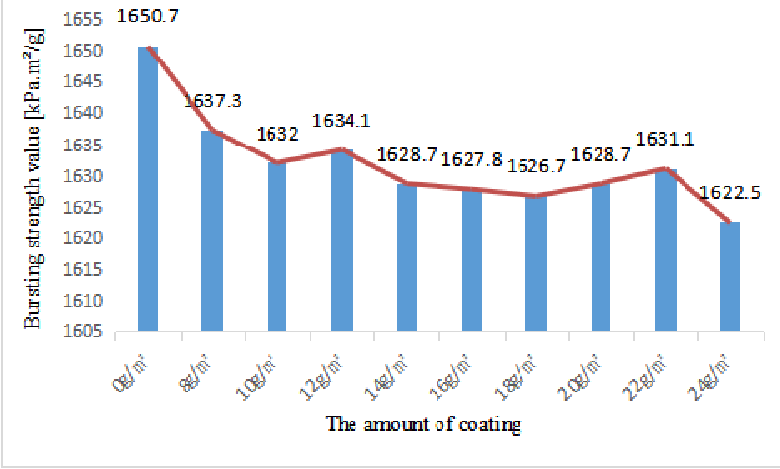

Fig. 7 The trend of bursting strength with coating

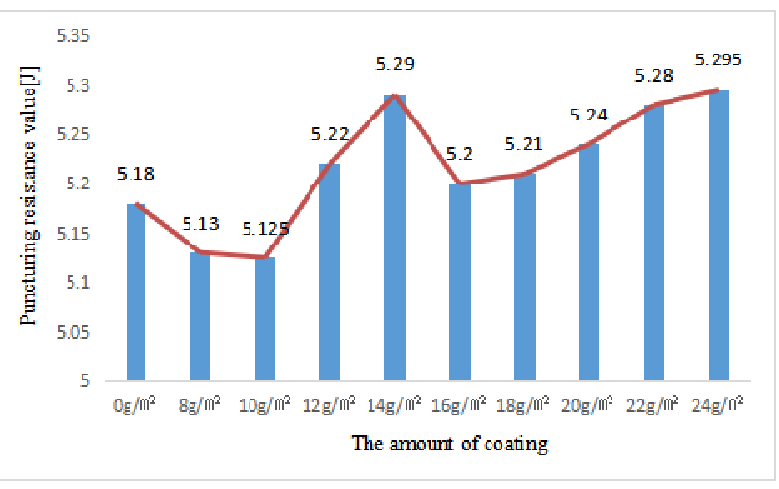

Fig. 8 The trend of puncturing strength with coating 
Fig. 7 is the analysis of the bursting strength, and Fig. 8 shows the puncture strength analysis. As can be seen from Fig. 7, when coating started, with the increase in the coating weigh the bursting strength slightly decreased and the decline in the value is very small, but it has a rising trend in coating weight $18-22 \mathrm{~g} / \mathrm{m}^{2}$. From Fig. 8 can be obviously seen, after coating, paperboard puncturing strength increased with the increase in the coating weigh, the overall strength has increased. Lead to increased strength performance may be because of the coating, the adhesion between the fibers is compact and the relative combined area increase, thus the adhesion between the fiber increase.

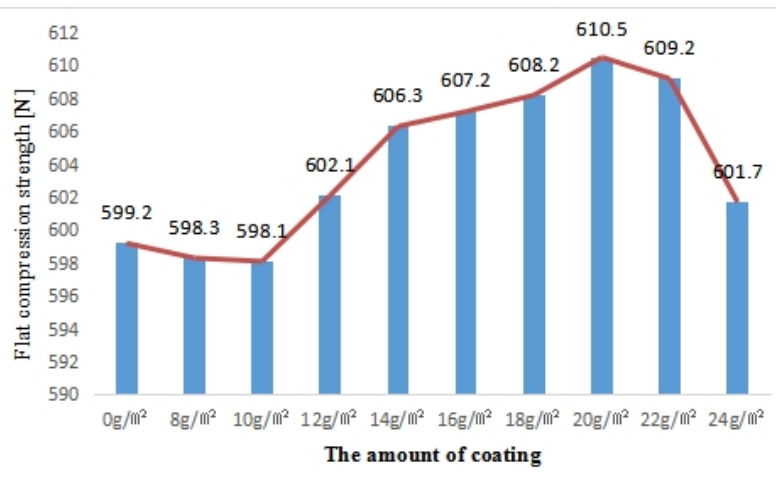

Fig. 9 The trend of flat compression strength with coating Fig. 10 The trend of edgewise-crushed resistance with coating

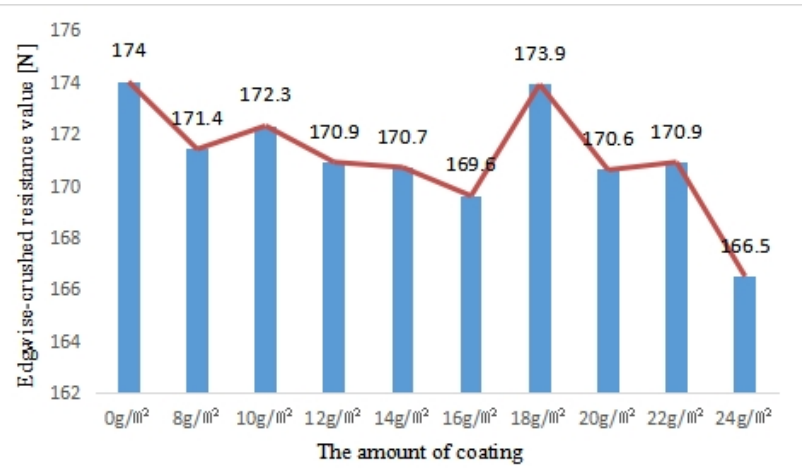

The analysis of flat compression strength and edgewise-crushed resistance of coated paperboard with different coating weigh is shown in Fig. 9 and Fig. 10. As can be seen from Fig. 9, flat compression strength before $20 \mathrm{~g} / \mathrm{m}^{2}$ increased with the increase in the coating weigh. After $20 \mathrm{~g} / \mathrm{m}^{2}$ increasing in the coating weigh, flat compression strength began to decline, but from this point of view, coating weight $20 \mathrm{~g} / \mathrm{m}^{2}$ is the best. Can be seen from Fig. 10, the coating weigh slightly affects the edgewise-crushed resistance as a whole, its growth rate is smaller and steady, and the performance of the coated paperboard with coating weight $18 \mathrm{~g} / \mathrm{m}^{2}$ is better.

\section{Conclusions}

Experiments showed that antisulphuric packaging paperboard which coating weigh is $18-22 \mathrm{~g} / \mathrm{m}^{2}$ was use for wrapping industrial silver products, its comprehensive protective effect and physical properties of the coated paperboard are better. It can avoid the economic loss caused by the corrosion of silver products due to exposure to the industrial atmosphere.

\section{References}

[1] Yong Shen, Huifang Zhang, Liming Wang et al. Journal of Shanghai and Technology University, 2005(19), p. 130-131 (In Chinese)

[2] Min Wang. Paper and Paper Making, 2003,4, p. 46-50 (In Chinese)

[3] Xiancheng Li. Journal of Materials Protection, 2002,35(11), p. 61-62 (In Chinese)

[4] Yunji Huang. China Pulp \& Paper, 1997(9), p. 57-64 (In Chinese)

[5] Zhiliang Zhang, Shan-mei Chen. Chinese Journal of Chemical Physics, 2003,16(2), p. 150-155 (In Chinese)

[6] Xuemei Liu, Fuxin Yany, Feng-xian Wang. Packaging Engineering, 2012,33(21), p. 11-14 (In Chinese)

[7] Shiju Yuan. Hubei Paper Making, 2004(1), p. 6-10 (In Chinese) 